\title{
Early Onset Epilepsy and Inherited Metabolic Disorders: Diagnosis and Management
}

\author{
Asuri N. Prasad, G.F. Hoffmann
}

\begin{abstract}
Epileptic encephalopathies presenting in early life present a diagnostic and therapeutic challenge. These disorders present with multiple seizure types that are treatment resistant and associated with significant abnormalities on electroencephalographic studies. The underlying etiology in many cases may be related to an inborn error of metabolism. Efforts to establish the specific diagnosis of a genetic defect or an inborn error of metabolism often results in requests for a vast array of biochemical and molecular tests leading to an expensive workup. In this review, we present the clinician with information that provides a rationale for a selective and nuanced approach to biochemical assays, and initial treatment strategies while waiting for a specific diagnosis to be established. A careful consideration of the presentation, identification of potentially treatable conditions, and consultation with the biochemical genetics laboratory can lead to a greater measure of success while limiting cost overruns. Such a targeted approach is hoped will lead to an early diagnosis and appropriate interventions.
\end{abstract}

RÉSUMÉ: Diagnostic et traitement de l'épilepsie à début précoce dans les maladies métaboliques héréditaires. Les encéphalopathies épileptiques qui surviennent en bas âge présentent un défi diagnostique et thérapeutique. Plusieurs types de crises convulsives résistantes au traitement se retrouvent dans ces maladies et les études électroencéphlographiques démontrent qu'ils sont associés à des anomalies importantes. Dans plusieurs cas, l'étiologie sous-jacente peut être liée à une erreur innée du métabolisme. Les efforts pour établir le diagnostic d'un défaut génétique ou d'une erreur innée du métabolisme donnent souvent lieu à une panoplie de tests biochimiques et moléculaires, donc à un bilan coûteux. Dans cette revue, nous présentons des informations qui fournissent une approche sélective et nuancée aux tests biochimiques et aux stratégies initiales de traitement en attendant qu'un diagnostic précis soit posé. Une étude soigneuse du mode de présentation, l'identification de maladies potentiellement traitables et la consultation du laboratoire de biochimie génétique peut améliorer les chances de succès et minimiser les coûts. Une approche mieux ciblée favorisera, nous l'espérons, un diagnostic précoce et des interventions appropriées.

Can. J. Neurol. Sci. 2010; 37: 350-358

\section{RATIONALE AND INTRODUCTION}

Epilepsy associated with inborn errors of metabolism (IEM) are characterized by the following clinical features; 1) frequent presentation in the neonatal period, infancy or early childhood years, 2) persistent neurological and functional impairment in all developmental domains, coinciding or associated with the occurrence of frequent clinical and or subclinical seizures, 3) resistance to conventional antiepileptic therapy, 4) adverse effects on cognition, and long term developmental outcomes ${ }^{1,2}$. Electroencephalographic records show variable features; diffusely abnormal and slow background rhythms, generalized attenuation of background rhythms, superimposed on which paroxysmal multifocal and or generalized epileptiform abnormalities of varying severity may be noted ${ }^{2-4}$. In this group of disorders, one may include catastrophic epilepsy syndromes (Ohtahara syndrome, West syndrome, etc). Imaging studies,

From the Clinical Neurosciences (ANP), Department of Pediatrics, Schulich School of Medicine and Dentistry, University of Western Ontario, London, Ontario, Canada; Department of General Pediatrics (GFH), University Children's Hospital, Heidelberg, Germany.

Received September 10, 2009. Final Revisions Submitted December 21, 2009. Correspondence to: Asuri N. Prasad, Clinical Neurosciences, Department of Pediatrics, Schulich School of Medicine and Dentistry, University of Western Ontario, 800 Commissioner Rd. East, London, Ontario, N6C 4A5, Canada. 
particularly magnetic resonance imaging (MRI) may or may not reveal associated structural abnormalities. The clinical challenge lies in establishing the specific diagnosis of an inborn error of metabolism without which specific interventions (at least for the treatable disorders) would not be possible, and critically important questions regarding the long-term prognosis and outcomes cannot be outlined for families. While most conditions are recessively inherited, other conditions may follow nonmendelian inheritance (e.g. mitochondrial disorders) in some instances the inheritance pattern has not been delineated (folinic acid responsive epilepsy). The precise delineation of a molecular diagnosis can be of the greatest importance for future family planning. For the purposes of discussion, we will henceforth refer to this group of disorders associated with severe epilepsy as metabolic epileptic encephalopathies.

Metabolic epileptic encephalopathies display an age dependent susceptibility and expression in the clinical phenotype. This age dependent vulnerability is related in part to the sequential development of excitatory and inhibitory pathways in the neonatal brain ${ }^{5}$. The initial excitatory role for gamma-aminobutyric acid (GABA) and its developmental switch from an excitatory to inhibitory role is dependent on the maturation of the cation chloride co transporter (KCC2). These changes are followed by the slightly later development of a glutamatergic related excitatory drive resulting in a time window during which the immature brain displays an imbalance in favor of excitability 6,7 . Many inborn errors of metabolism are accompanied by metabolic perturbations that tilt the balance further to the point of epileptogenesis and ictogenesis.

There is a need to establish the rationale for a clinical and investigational approach to diagnosis and management, to allow pediatricians and neonatologist to proceed on a more informed basis, by prioritizing rather than ordering a large number of investigations. A systematic approach such as the one suggested (Figure 1) and discussed in this paper is likely to maximize the diagnostic yield, with a higher priority for potentially treatable conditions in the diagnostic work-up. Careful consideration and consultation with a metabolic geneticist, and the neurometabolic laboratory can be invaluable in directing the course of investigations and treatment.

The various inherited metabolic disorders that are known to present as epileptic encephalopathy in the neonate and infant are listed in Tables 1 and 2. The underlying biochemical defects involve many different pathways and link through known and

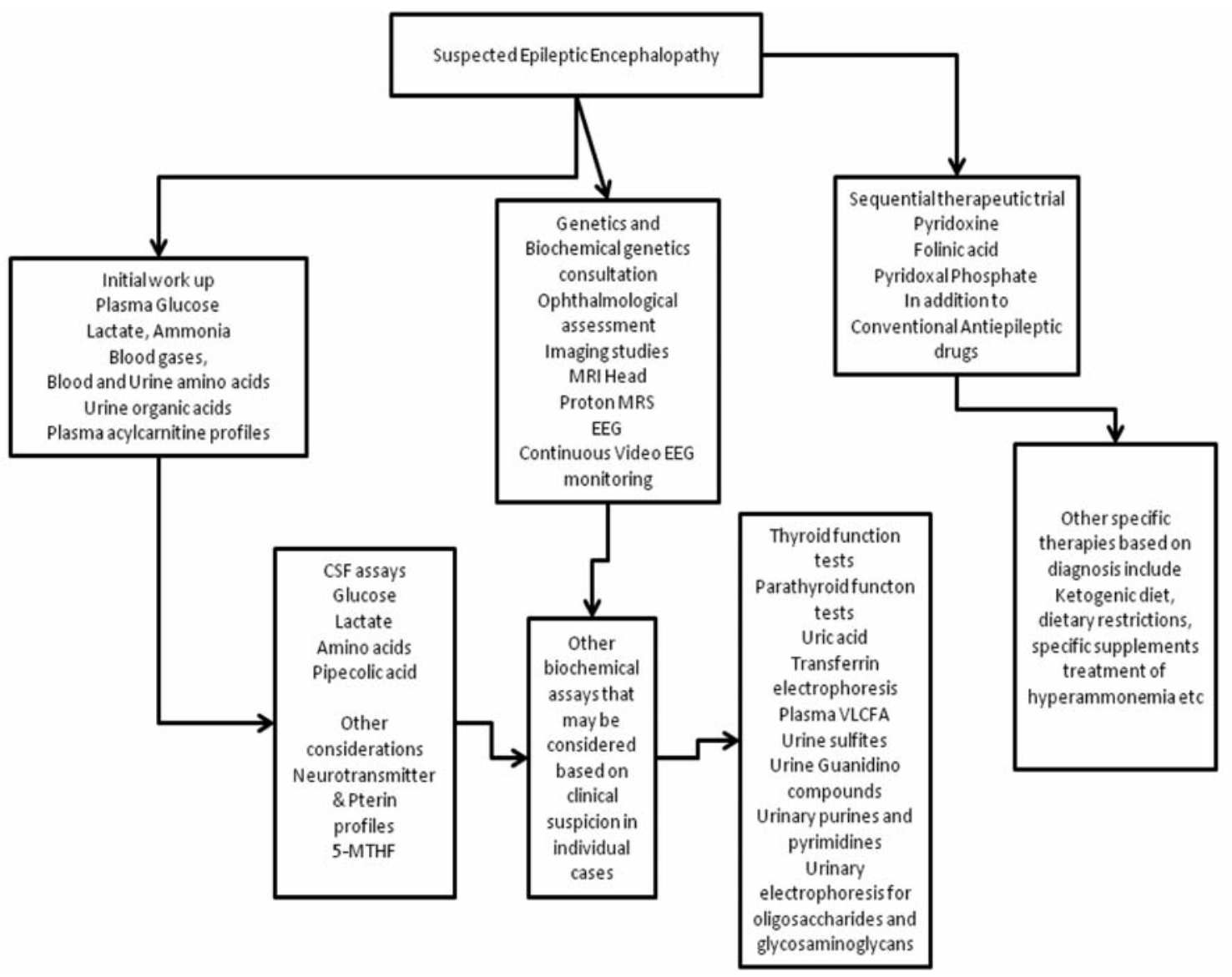

Figure 1: Proposed scheme of investigation and initial management in epilepsy associated with inborn errors of metabolism. CSF $=$ Cerebrospinal fluid, 5-MTHF= 5-Methyltetrahydrofolate, VLCFA= Very Long Chain Fatty Acids, MRS= Magnetic Resonance Spectroscopy, EEG= Electroencephalography. 
Table 1: Neonatal epileptic encephalopathy - causes

\begin{tabular}{l}
\hline Nesidioblastosis \\
Urea Cycle Disorders \\
Non-ketotic hyperglycinemia \\
Developmental Delay, epilepsy and Neonatal Diabetes (DEND) \\
Hyperinsulinism, Hyperammonemia (HI/HA) \\
Propionic, Methylmalonic and Isovaleric Acidurias \\
Maple Syrup Urine Disease \\
Pyridoxine-dependant Epilepsy (Piperideine--6-carboxylate \\
$\quad$ Dehydrogenase Deficiency \\
Folinic Acid Responsive Seizures \\
Pyridoxal phosphate-dependent Epilepsy (Pyridox(am)ine 5- \\
$\quad$ phosphate Oxidase Deficiency) \\
Biotinidase Deficiency \\
Perinatal Hypophosphatasia \\
Adenylsuccinate Lyase Deficiency \\
Methylene tetrahydrofolate Reductase Deficiency (MTHFR \\
$\quad$ Deficiency) \\
D-2-Hydroxyglutaric Aciduria \\
Congenital Disorders of Glycosylation \\
3-Phosphoglycerate Dehydrogenase Deficiency \\
GABA-Transminase Deficiency \\
Congenital Glutamine Deficiency \\
Glutamate Transporter Deficiency \\
Neonatal Ceroidlipofuscinosis with Cathepsin Deficiency \\
(Creatine Deficiency Disorders)
\end{tabular}

The conditions highlighted in bold are more common and those in italic are potentially treatable.

unknown mechanisms in creating an epileptogenic state. Readers are advised to refer to a detailed discussion of these issues in review articles ${ }^{8,9}$. Most importantly, the majority of disorders in the neonatal age group are amenable to specific rational therapy: 13 out of 20 in total (Table 1) and four out of five of the more common entities: nesidioblastosis, urea cycle disorders, propionic, methylmalonic and isovaleric acidurias and maple syrup urine disease. Only non-ketotic hyperglycinemia can still be considered untreatable. In infancy, 10 out of 21 disorders are treatable as indicated in Table 2.

\section{Inborn errors of metabolism and "epilepsy syndromes"}

A wide variation in phenotypic expression is seen in terms of age of onset and seizure type in different IEMs. Variables that influence clinical presentation include the severity of enzyme deficiency, as well as the site of the metabolic block and its consequences; both immediate (deficiency of a critical substrate, accumulation of a neurotoxic intermediary), and remote (which are incompletely understood in most cases). Manifestation occur in-utero, at birth or thereafter in the first year of life. In-utero, seizures are often reported as abnormal and exaggerated fetal movements by the mother. After birth, affected infants present with features of an epileptic encephalopathy with altered sensorium, changes in muscle tone, irregular breathing, hiccups,
Table 2: Infantile metabolic encephalopathy - causes

\begin{tabular}{l}
\hline GLUT1 Deficiency \\
Urea Cycle Disorders \\
Non-ketotic Hyperglycinemia \\
Propionic, Methylmalonic and Isovaleric Acidurias \\
2-Methyl-3-hydroxybutyryl-CoA Dehydrogenase (MHBD) Deficiency \\
Maple Syrup Urine Disease \\
Pyridoxine-dependant Epilepsy \\
Pyridoxal phosphate-dependent Epilepsy \\
Biotinidase Deficiency \\
Untreated Classical Phenylketonuria as well as Pterin Defects \\
Menke Disease \\
Sulphite Oxidase/ Molybdenum Cofactor Deficiency \\
Generalized Peroxisomal Disorders \\
Mitochondriopathies (especially MERRF) \\
Congenital Disorders of Glycosylation \\
Adenylsuccinate Lyase Deficiency \\
D-2-Hydroxyglutaric Aciduria \\
MTHFR Deficiency \\
Creatine Deficiency Disorders \\
Infantile Neuronal Ceroid Lipofuscinoses (NCL) \\
Lysosomal Diseases
\end{tabular}

The conditions highlighted in bold are more common and those in italic are potentially treatable.

apnea, autonomic disturbances, and multiple seizure types. Systemic disturbances are often present in the toxic encephalopathies due to urea cycle defects, organic acidurias and maple syrup urine disease ${ }^{9}$. In this context, many infants may be misdiagnosed as having hypoxic ischemic encephalopathy or sepsis in neonatal units.

Age dependent expression of epilepsy syndromes is well recognized in the presentation of epilepsy associated with different inborn errors of metabolism. For instance, glycine encephalopathy is well known to present with early myoclonic encephalopathy (EME), while early infantile epileptic encephalopathy (EIEE) has been reported in adenylosuccinase deficiency ${ }^{10,11}$. At other times, the disorders present for the very first time with infantile spasms after the neonatal period. Those presenting in the neonatal period with severe seizures and encephalopathy often display evolution to infantile spasms with age. Further evolution into mixed seizure types (clonic, tonic, tonic clonic, atonic and myoclonic seizures) is also documented when patients survive beyond infancy ${ }^{12}$.

The seizure phenotype thus can be seen to evolve over time to fit descriptions of different epilepsy syndromes such as EME evolving into infantile spasms in nonketotic hyperglycinemia, and focal seizures-evolving into infantile spasms in patients with Menkes disease $)^{13}$.

Electroencephalographic changes in severe epileptic encephalopathies range from disorganized and slow background 


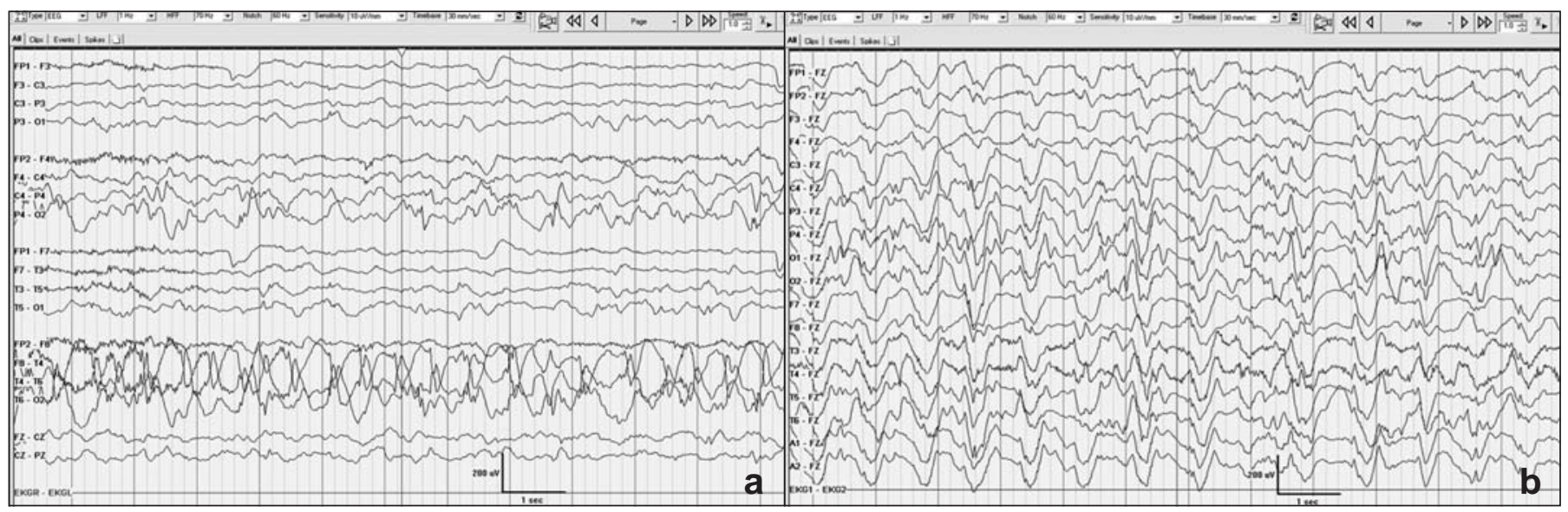

Figure 2: (a) Focal ictal rhythms at three-months and (b) generalized ictal rhythmic discharges that accompanied brief flexor spasms in a five-monthold infant with Menkes disease and a chronic epileptic encephalopathy.

rhythms, focal and multifocal epileptiform patterns, generalized abnormalities as well as suppression-burst patterns (Figure 2a,b).

The EEG findings can be strikingly abnormal but they lack specificity and overlapping findings are frequent in different IEMs with the exception of glycine encephalopathy. The EEG in glycine encephalopathy is consistently associated with periods of complete flattening of the background lasting three to ten seconds, with superimposed bursts of bilateral but asynchronous epileptiform patterns lasting one to five seconds in the context of a clinical presentation of myoclonic that is multifocal and erratic. The EEG patterns of glycine encephalopathy show suppression burst mainly in sleep, and the duration of suppression is longer than encountered in other conditions ${ }^{14}$. In many instances, these patterns evolve into hypsarrhythmia while the seizures evolve into infantile spasms.

\section{Biochemical investigation of epileptic encephalopathies}

Inherited metabolic disorders presenting in the neonatal period and infancy are listed in Tables 1 and 2. A detailed description of the biochemical and clinical features of each of these conditions is beyond the scope of this discussion. The initial investigations in all cases should include estimation of blood glucose, electrolytes (calcium, magnesium), lactate and ammonia. The early detection of hypoglycemia, hypocalcemia, hyperammonemia and its management is critical to effectively manage seizures and to prevent the development of further neuronal injury and long-term developmental sequelae. Two disorders are of particular interest as there may be specific targeted treatments available. The condition of developmental delay, epilepsy and neonatal diabetes (DEND), is related to mutations in the gene encoding a specific ATP sensitive $\mathrm{K}$ channel subunit Kir6.2 (KCNJ11) can be treated with a sulfonylurea $^{15-18}$. The second is a form of congenital hyperinsulinism associated with hyperammonemia ${ }^{19,20}$, which is dominantly inherited and related to a gain of function mutations in the enzyme glutamate dehydrogenase (GDH). The hyperinsulinism responds to treatment with diazoxide. Affected individuals may manifest with generalized seizures beyond the neonatal period unrelated to the hypoglycemia ${ }^{21,22}$. Abnormalities in quantitative assays for acylcarnitines, plasma amino acids and urine organic acids should lead to identification of markers for organic acidurias, aminoacidopathies, urea cycle defects, and primary disorders of energy metabolism. While these early investigations are drawn, access to EEG monitoring in the neonatal unit is important for the detection and treatment of seizure activity. While most neonatal units are currently able to access routine EEG studies, prolonged or continuous monitoring under video surveillance is becoming feasible and gaining in significance. This is in part due to the recognition of subclinical and electrographic seizures that are more frequently overlooked unless specifically monitored for in the newborn period $^{23,24}$. The phenomenon of electroclinical dissociation during treatment makes it difficult to pick up electrographic seizures without continuous EEG monitoring ${ }^{25}$. Amplitude integrated EEG and compressed spectral array analysis may well be on their way to being utilized as the first line screen for the detection of seizure activity ${ }^{23,26}$.

If the initial metabolic investigations exclude hypoglycemia, hypocalcemia, hypomagnesemia, elevations of lactate and ammonia, the focus of investigation and management should continue to vigorously search for treatable epileptic encephalopathies (Tables 1-3). It then becomes important to investigate for total homocysteine levels (MTHFR deficiency) and biotinidase deficiency as these are not reliably included in amino and organic acid determinations. At present, with the discovery of biochemical markers for pyridoxine dependent epilepsy, folinic acid dependent epilepsy as well as pyridoxine resistant pyridoxal-phosphate dependent epilepsy, a lumbar puncture should be carried out next.

A sequential therapeutic trial with vitamin $\mathrm{B}_{6}$, folinic acid and pyridoxal phosphate should be instituted early and should be mandatory in every case that exhibits the features of an epileptic encephalopathy and failure of a sustained response to antiepileptic treatment. The current recommendations from 
Table 3: Biochemical markers that can be assayed in blood and body fluids, and their clinical significance

\begin{tabular}{|c|c|c|}
\hline Metabolite & Change & Relevant to the diagnosis of: \\
\hline $\begin{array}{l}\text { HVA, 5-HIAA, } \\
\text { arginine } \\
\text { Lactate, alanine, 3- } \\
\text { O-methyl-dopa, } \\
\text { threonine, }\end{array}$ & $\begin{array}{l}\text { Decreased } \\
\text { Increased }\end{array}$ & PNPO deficiency \\
\hline $\begin{array}{c}\text { Glycine } \\
\text { (Plasma \& CSF) }\end{array}$ & Increased & Nonketotic Hyperglycinemia \\
\hline Purines (Urine) & Increased & Adenylsuccinate lyase deficiency \\
\hline $\begin{array}{c}\text { Homocysteine and } \\
\text { MTHF } \\
\text { (Blood \& CSF) }\end{array}$ & $\begin{array}{l}\text { Elevated homocysteine in blood } \\
\text { Reduced MTHF in CSF }\end{array}$ & MTHFR deficiency \\
\hline GABA (CSF) & Increased & GABA transaminase deficiency \\
\hline Glutamine (CSF) & Low & Congenital glutamine deficiency \\
\hline $\begin{array}{l}\text { Pipecolic acid (CSF } \\
\text { and Blood) }\end{array}$ & elevated & $\mathrm{B}_{6}$ dependant seizures \\
\hline CSF glucose & $\begin{array}{c}\text { Hypoglycorrachia }(<35 \mathrm{mg} / \mathrm{dL} \text { or }<2 \mathrm{mM}) \\
\text { CSF/ Blood Glucose-Ratio }<0.35(0.65 \\
\pm 0.1)\end{array}$ & Glucose transporter deficiency (GLUT1) \\
\hline Lactate & Elevated & Mitochondriopathies \\
\hline Alanine, Threonine & Elevated & Mitochondriopathies \\
\hline Serine & Reduced & Serine Synthesis Defects (G3PDH) \\
\hline $\begin{array}{l}\text { Biogenic } \\
\text { monoamine } \\
\text { metabolites }\end{array}$ & $\begin{array}{l}\text { Changes in the concentration of } 3 \mathrm{OMD}, \\
\text { L-DOPA, } 5 \mathrm{HTP}, 5 \mathrm{HIAA}, \mathrm{HVA}, \mathrm{MHPG} \text { and } \\
\text { characteristic profiles can be identified for } \\
\text { instance reflecting disturbances of } \\
\text { dopamine and serotonin turnover }\end{array}$ & Neurotransmitter disorders \\
\hline $\begin{array}{l}\text { Methylation } \\
\text { pathway } \\
\text { metabolites }\end{array}$ & Low & $\begin{array}{l}\text { 5-methytetrahydrofolate reductase } \\
\text { deficiency, acquired or congenital } \\
\text { cerebral folate deficiency, cerebral } \\
\text { folate transport defect }\end{array}$ \\
\hline
\end{tabular}

3OMD=3-O-methylDOPA, L-DOPA,= Levodopa, HVA=Homovanillic acid, 5HTP=5 -Hydroxytryptophan, MHPG=3-hyrdoxy 4-methoxy propylglycol, PNPO=Pyridox(am)ine 5'-phosphate oxidase, MTHFR=Methylene tetrahydrofolate reductase, 5 -HIAA $=5$-hydroxyindole acetic acid.

recent studies suggest that the initial administration of $100 \mathrm{mg}$ of pyridoxine intravenously during EEG monitoring (Figures 3a-c) (preferably in the neonatal intensive care unit as there is a risk of apnea in cases of pyridoxine dependency) should be followed by oral administration of pyridoxine $30 \mathrm{mg} / \mathrm{kg}$ daily for five to seven days; folinic acid should also be given simultaneously at the doses of $3-5 \mathrm{mg} / \mathrm{kg} / \mathrm{day}^{27}$. Folinic acid and pyridoxine responsive epilepsy are considered now to be allelic conditions. Several patients with folinic acid responsive seizures have now been shown to be positive for the urinary biochemical marker $(\alpha-$ aminoadipic semialdehyde (AASA), and for pathogenic mutations in the antiquitin gene. In addition, patients with folinic acid responsive epilepsy have initially responded to pyridoxine, only to experience seizure recurrences that have responded to subsequent addition of folinic acid. Furthermore, the mortality rate has been high for some patients with folinic acid responsive epilepsy. For these reasons, current recommendations suggest using both pyridoxine and folinic acid in combination for a therapeutic trial. Simultaneously initiated investigations should include a search for pipecolic acid in blood and cerebrospinal fluid $(\mathrm{CSF})^{28}$. Failure of response to these measures should be followed through by a trial with administration of pyridoxal phosphate $50 \mathrm{mg} / \mathrm{kg}$ for three days ${ }^{29}$.

Cerebrospinal fluid analysis in the investigation of epileptic encephalopathies

In addition to ruling out infection, CSF should be screened for glucose, amino acids, lactate, pipecolic acid, 5- 


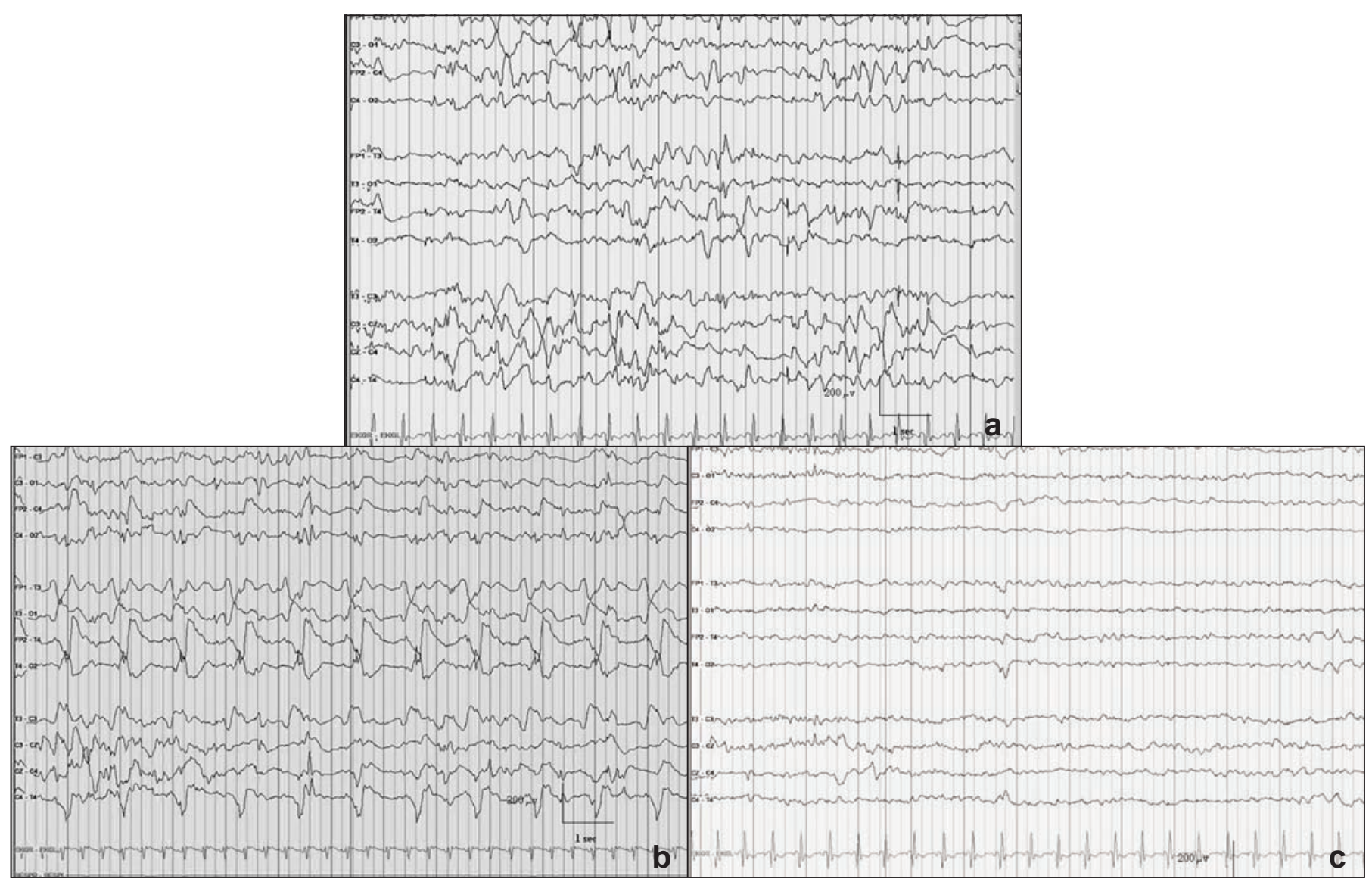

Figure 3: (a) EEG recording in an infant with epileptic encephalopathy, showing poorly organized background and multifocal spike complexes, (b) ictal rhythms in the same patient, there were no clinical manifestations, and (c) after an injection of pyridoxine 100 mg administered intravenously, under monitoring, there is a dramatic response with cessation of spike activity and seizure remission.

methyltetrahydrofolate as well as neurotransmitter and pterin profile. Glucose and amino acids must be determined in blood simultaneously ${ }^{30}$. Cerebrospinal fluid abnormalities serve as biochemical markers for several inherited metabolic disorders (Table 3); hypoglycorrhachia (glucose transporter GLUT1 deficiency) ${ }^{31}$, elevated lactate (disorders of energy metabolism $)^{32}$, elevated CSF pipecolic acid in CSF, plasma and urine (pyridoxine dependent epilepsy) ${ }^{33}$. An abnormal neurotransmitter profile in the CSF, e.g. low levels of HVA (homovanillic acid), MHPG (3-methyl-4-hydroxyphenylglycol), and HIAA (5-hydroxyindoleacetic acid), and elevated levels of lactate, alanine, threonine and glycine suggests pyridoxalphosphate dependent epilepsy) ${ }^{34,35}$. Cerebrospinal fluid neurotransmitter profiles are useful in establishing a snapshot of the state of catecholamine biosynthesis and metabolism in the brain. The findings have to be corroborated with clinical picture and the findings of biochemical assays of other body fluids.

The assay for 5-methyltetrahydrofolate is useful in establishing the diagnosis and monitoring of cerebral folate deficiency states $^{36}$, while CSF pterin profiles are very useful in the diagnosis of tetrahydrobiopterin related defects which include; deficiency of GTP cyclohydrolase I, 6-pyruvoyl tetrahydropterin synthase, sepiapterin reductase, dihydropteridine reductase (DHPR) and pterin- $4 \alpha$-carbinolamine dehydratase. With the exception of the last condition which is benign, autosomal dominant deficiency of GTP cyclohydrolase and autosomal recessive sepiapterin reductase manifest with deficiency of $\mathrm{BH}_{4}$ only in the brain. The others are accompanied by elevated phenylalanine levels in the blood ${ }^{37}$. Special attention must be paid to the appropriate collection and processing and transport of CSF samples to the reference laboratory.

\section{Non-specific metabolic encephalopathies}

Once the treatable and acute toxic encephalopathies are excluded, one is often faced with the situation of chronic epilepsy with non specific encephalopathic features. In this situation, it is important to again emphasize the importance of a careful history, family pedigree, and physical examination. The presence of dysmorphic facial features, abnormal fat pads, and inverted nipples for instance would suggest congenital disorders of glycosylation, while respiratory abnormalities may indicate an associated metabolic disturbance of $\mathrm{pH}$ regulation. The presence of hepatosplenomegaly, hypotonia and dysmorphic features suggests lysosomal or peroxisomal disorders. An 
Table 4: Laboratory indicators of neurometabolic disorders

\begin{tabular}{ll}
\hline Lab abnormality & Relevant Metabolic Disorder \\
\hline Alkaline phosphatase (Increased) & Hypoparathyreoidism, Bile acids synthesis defects \\
\hline Anemia (macrocytic) & Disturbances in B $_{12}$ - or folic acid metabolism \\
\hline Retikulocytosis & Glycolysis defects, Glutathione synthesis defects \\
\hline Vacuolized lymphocytes & Lysosomal storage disorders \\
\hline Uric acid (decreased) & $\begin{array}{l}\text { Molybdenum cofactor deficiency, Disorders of } \\
\text { purine metabolism }\end{array}$ \\
\hline Uric acid (Increased) & $\begin{array}{l}\text { Glycogen storage disorders, Disorders of purine } \\
\text { metabolism, Fatty acid oxidation defects, } \\
\text { Mitochondriopathies }\end{array}$ \\
\hline Low T4, Increase TSH & Mitochondriopathies \\
\hline Low PTH/Hypocalcemia & Congenital disorders of Glycosylation \\
\hline
\end{tabular}

ophthalmological examination is required to rule out lens subluxation (sulfite oxidase and molybdenum cofactor deficiency $)^{38-40}$. Additional tests may be called for at this stage; assays for plasma very long chain fatty acids (peroxisomal disorders) ${ }^{41,42}$, transferrin electrophoresis (disorders of glycosylation), pre and post prandial assays for lactate, urinary sulfites (dipstick) (sulfite oxidase deficiency), urinary guanidino compounds (disorders of creatine biosyntheses), urinary purines and pyrimidines (disorders of purine and pyrmidine biosynthesis and degradation), and finally electrophoresis for glycosaminoglycans and oligosaccharides in the urine (mucopysaccharidoses, oligosaccharidoses). Additional clues to the presence of inherited metabolic disorders can be obtained through a systematic search for laboratory markers for thyroid and parathyroid dysfunction (markers for mitochondrial and CDG syndromes), uric acid levels (increased in glycogen storage disorders, disorders of purine metabolism, fatty acid oxidation defects, and reduced in sulfite oxidase deficiency and molybdenum co-factor deficiency). These associations are listed in Table 4. Invasive procedures such as skin and muscle biopsies may be reserved until the later stages of investigation. Ultrastructural abnormalities in the skin and muscle may reveal diagnostic clues to inborn errors of metabolism. Biochemical assays on fresh muscles are necessary to diagnose defects in the respiratory chain, while many specific enzyme assays can be carried out in fibroblast cultures.

\section{Magnetic resonance spectroscopy in the investigation of epileptic encephalopathies}

Access to cranial tomography (CT) and MRI is almost universal. Their combined use can not only be useful in the detection of structural brain malformations, as findings can be especially relevant in the investigation of epileptic metabolic encephalopathies. Proton MRS is gaining importance as the study can be combined with MRI studies and performed in a single setting. It is able to non-invasively identify several metabolite peaks related to metabolic encephalopathies. A reduced or absent creatine peak (cerebral creatine deficiency ${ }^{43}$, an abnormal inverted doublet peak suggestive of lactate elevation (mitochondrial disorders $)^{44,45}$, or glycine elevation (glycine encephalopathy) are of particular value ${ }^{46,47}$. MRS studies have also been used to monitor response to treatment in cerebral creatine deficiency and 3-phosphoglycerate dehydrogenase deficiency ${ }^{48}$.

\section{Conclusions}

The clinical and EEG considerations to recognize a metabolic epileptic encephalopathy in the newborn and infant are delineated. Disorders that should be considered in the evaluation of an epileptic encephalopathy are listed by age of presentation. Different specialized assays of metabolites in body fluids; blood, urine, and cerebrospinal fluid should be carried out sequentially, priority should be given on the basis of age at presentation, and the need to identify potentially treatable conditions, so that neurological injury can be minimized.

Time is especially precious, when faced with disorders such as urea cycle defects, as the recognition and early treatment of hyperammonemia is critical in influencing survival and longterm outcomes. In a long-term outcome study on patients treated for urea cycle defects in Central Europe, early death was reported in $49 \%$, and mortality ten years after diagnosis reached $85 \%$. The strongest predictors of IQ $<70$, i.e. mental retardation, were levels of $\mathrm{NH}_{3} \geq 500 \mu \mathrm{mol} / 1$ at diagnosis and the duration of coma (days) $x \mathrm{NH}_{3} \geq 4000^{49,50}$.

Amongst the treatable conditions; vitamin dependent epilepsies (biotinidase, pyridoxine, pyridoxal-phosphate and folinic acid), cerebral creatine deficiency, GLUT1 transporter deficiency and 3-phosphoglycerate dehydrogenase deficiency are important early considerations. In the management of these conditions early diagnosis offers the chance of timely and specific interventions through vitamin supplementation or diets. In the remaining disorders, treatment is usually symptomatic and along schemes of management with antiepileptic drug therapy, detailed consideration of which is beyond the scope of the current discussion. 


\section{REFERENCES}

1. Dulac O. Epileptic encephalopathy. Epilepsia. 2001;42 Suppl 3: 23-6.

2. Nabbout R, Dulac O. Epileptic encephalopathies: a brief overview. J Clin Neurophysiol. 2003 Nov-Dec;20(6):393-7.

3. Hrachovy RA, Frost JD, Jr. Infantile epileptic encephalopathy with hypsarrhythmia (infantile spasms/West syndrome). J Clin Neurophysiol. 2003 Nov-Dec;20(6):408-25.

4. Ohtahara S, Yamatogi Y. Epileptic encephalopathies in early infancy with suppression-burst. J Clin Neurophysiol. 2003 NovDec;20(6):398-407.

5. Holmes GL, Ben-Ari Y. The neurobiology and consequences of epilepsy in the developing brain. Ped Res. 2001 Mar;49(3): 320-5.

6. Dzhala VI, Talos DM, Sdrulla DA, Brumback AC, Mathews GC, Benke TA, et al. NKCC1 transporter facilitates seizures in the developing brain. Nat Med. 2005 Nov;11(11): 1205-13.

7. Sankar R. A time to convulse, a time to stop em leader. Epilepsy Curr. 2003 May;3(3):82-3.

8. Pearl PL. New treatment paradigms in neonatal metabolic epilepsies. J Inherit Metab Dis. 2009 Apr;32(2):204-13.

9. Prasad A, Prasad C. Linking biochemical pathways to seizure susceptibility in early life; lessons from inborn errors of metabolism. In: Takahashi T, Fukuyama Y, editors. Biology of seizure susceptibility in the developing brain. Montrouge: John Libbey Eurotext. 2008. p. 101-27.

10. Köhler M, Assmann B, Bräutigam C, Storm W, Marie S, Vincent $\mathrm{MF}$, et al. Adenylosuccinase deficiency: possibly underdiagnosed encephalopathy with variable clinical features. Eur J Paediatr Neurol. 1999;3(1):3-6.

11. Wolf NI, Bast T, Surtees R. Epilepsy in inborn errors of metabolism. Epileptic Disord. 2005 Jun;7(2):67-81.

12. Vigevano F, Bartuli A. Infantile epileptic syndromes and metabolic etiologies. J Child Neurol. 2002 Dec;17 Suppl 3:3S9-13; discussion 3S4.

13. Bahi-Buisson N, Kaminska A, Nabbout R, Barnerias C, Desguerre I, De Lonlay P, et al. Epilepsy in Menkes disease: analysis of clinical stages. Epilepsia. 2006 Feb;47(2):380-6.

14. Chen PT, Young C, Lee WT, Wang PJ, Peng SS, Shen YZ. Early epileptic encephalopathy with suppression burst electroencephalographic pattern--an analysis of eight Taiwanese patients. Brain Dev. 2001 Nov;23(7):715-20.

15. Gloyn AL, Diatloff-Zito C, Edghill EL, Bellanné-Chantelot C, Nivot S, Coutant R, et al. KCNJ11 activating mutations are associated with developmental delay, epilepsy and neonatal diabetes syndrome and other neurological features. Eur J Hum Genet. 2006 Jul;14(7):824-30.

16. Bahi-Buisson N, Eisermann M, Nivot $\mathrm{S}$, Bellanné-Chantelot $\mathrm{C}$, Dulac O, Bach N, et al. Infantile spasms as an epileptic feature of DEND syndrome associated with an activating mutation in the potassium adenosine triphosphate (ATP) channel, Kir6.2. J Child Neurol. 2007 Sep;22(9):1147-50.

17. Proks P, Arnold AL, Bruining J, Girard C, Flanagan SE, Larkin B, et al. A heterozygous activating mutation in the sulphonylurea receptor SUR1 (ABCC8) causes neonatal diabetes. Hum Mol Gen. 2006 Jun 1;15(11):1793-800.

18. Shimomura K, Hörster F, de Wet H, Flanagan SE, Ellard S, Hattersley AT, et al. A novel mutation causing DEND syndrome: a treatable channelopathy of pancreas and brain. Neurology. 2007 Sep 25;69(13):1342-9.

19. Stanley CA, Lieu YK, Hsu BY, Burlina AB, Greenberg CR, Hopwood NJ, et al. Hyperinsulinism and hyperammonemia in infants with regulatory mutations of the glutamate dehydrogenase gene. N Engl J Med. 1998 May 7;338(19): 1352-7.

20. Stanley CA, Fang J, Kutyna K, Hsu BY, Ming JE, Glaser B, et al. Molecular basis and characterization of the hyperinsulinism/ hyperammonemia syndrome: predominance of mutations in exons 11 and 12 of the glutamate dehydrogenase gene. HI/HA Contributing Investigators. Diabetes. 2000 Apr;49(4):667-73.

21. Raizen DM, Brooks-Kayal A, Steinkrauss L, Tennekoon GI, Stanley CA, Kelly A. Central nervous system hyperexcitability associated with glutamate dehydrogenase gain of function mutations. J Pediatr. 2005 Mar;146(3):388-94.

22. Bahi-Buisson N, El Sabbagh S, Soufflet C, Escande F, Boddaert N, Valayannopoulos V, et al. Myoclonic absence epilepsy with photosensitivity and a gain of function mutation in glutamate dehydrogenase. Seizure. 2008 Oct;17(7):658-64.

23. Clancy RR. Prolonged electroencephalogram monitoring for seizures and their treatment. Clin Perinatol. 2006 Sep;33(3):64965 , vi.

24. Connell J, Oozeer R, de Vries L, Dubowitz LM, Dubowitz V. Continuous EEG monitoring of neonatal seizures: diagnostic and prognostic considerations. Arch Dis Child. 1989 Apr;64(4): $452-8$.

25. Scher MS, Alvin J, Gaus L, Minnigh B, Painter MJ. Uncoupling of EEG-clinical neonatal seizures after antiepileptic drug use. Pediatr Neurol. 2003 Apr;28(4):277-80.

26. Shah DK, Mackay MT, Lavery S, Watson S, Harvey AS, Zempel J, et al. Accuracy of bedside electroencephalographic monitoring in comparison with simultaneous continuous conventional electroencephalography for seizure detection in term infants. Pediatrics. 2008 Jun;121(6):1146-54.

27. Gallagher RC, Van Hove JL, Scharer G, Hyland K, Plecko B, Waters PJ, et al. Folinic acid-responsive seizures are identical to pyridoxine-dependent epilepsy. Ann Neurol. 2009 May;65(5): 550-6.

28. Struys EA, Jakobs C. Alpha-aminoadipic semialdehyde is the biomarker for pyridoxine dependent epilepsy caused by alphaaminoadipic semialdehyde dehydrogenase deficiency. Mol Genet Metab. 2007 Aug;91(4):405.

29. Bagci S, Zschocke J, Hoffmann GF, Bast T, Klepper J, Müller A, et al. Pyridoxal phosphate-dependent neonatal epileptic encephalopathy. Arch Dis Child Fetal Neonatal Ed. 2008 Mar;93 (2):F151-2

30. Hoffmann GF, Surtees RA, Wevers RA. Cerebrospinal fluid investigations for neurometabolic disorders. Neuropediatrics. 1998 Apr;29(2):59-71.

31. Seidner G, Alvarez MG, Yeh JI, O'Driscoll KR, Klepper J, Stump TS, et al. GLUT-1 deficiency syndrome caused by haploinsufficiency of the blood-brain barrier hexose carrier. Nat Genet. 1998 Feb;18(2):188-91.

32. Gillis L, Kaye E. Diagnosis and management of mitochondrial diseases. Pediatr Clin North Am. 2002 Feb;49(1):203-19.

33. Willemsen MA, Mavinkurve-Groothuis AM, Wevers RA, Rotteveel JJ, Jakobs C. Pipecolic acid: a diagnostic marker in pyridoxinedependent epilepsy. Ann Neurol. 2005 Oct;58(4):653.

34. Clayton PT, Surtees RA, DeVile C, Hyland K, Heales SJ. Neonatal epileptic encephalopathy. Lancet. 2003 May 10;361(9369):1614.

35. Mills PB, Surtees RA, Champion MP, Beesley CE, Dalton N, Scambler PJ, et al. Neonatal epileptic encephalopathy caused by mutations in the PNPO gene encoding pyridox(am)ine 5'phosphate oxidase. Hum Mol Gen. 2005 Apr 15;14(8):1077-86.

36. Verbeek MM, Blom AM, Wevers RA, Lagerwerf AJ, van de Geer J, Willemsen MA. Technical and biochemical factors affecting cerebrospinal fluid 5-MTHF, biopterin and neopterin concentrations. Mol Genet Metab. 2008 Nov;95(3):127-32.

37. Longo N. Disorders of biopterin metabolism. J Inherit Metab Dis. 2009 Jun;32(3):333-42.

38. Hobson EE, Thomas S, Crofton PM, Murray AD, Dean JC, Lloyd D. Isolated sulphite oxidase deficiency mimics the features of hypoxic ischaemic encephalopathy. Eur J Pediatr. 2005 Nov;164 (11):655-9.

39. Johnson JL, Waud WR, Rajagopalan KV, Duran M, Beemer FA, Wadman SK. Inborn errors of molybdenum metabolism: combined deficiencies of sulfite oxidase and xanthine dehydrogenase in a patient lacking the molybdenum cofactor. Proc Natl Acad Sci USA. 1980 Jun;77(6):3715-9.

40. Rupar CA, Gillett J, Gordon BA, Ramsay DA, Johnson JL, Garrett RM, et al. Isolated sulfite oxidase deficiency. Neuropediatrics. 1996 Dec;27(6):299-304.

41. Watkins PA, McGuinness MC, Raymond GV, Hicks BA, Sisk JM, Moser AB, et al. Distinction between peroxisomal bifunctional enzyme and acyl-CoA oxidase deficiencies. Ann Neurol. 1995 Sep;38(3):472-7. 
42. Van Maldergem L, Espeel M, Wanders RJ, Roels F, Gerard P, Scalais E, et al. Neonatal seizures and severe hypotonia in a male infant suffering from a defect in peroxisomal beta-oxidation. Neuromuscul Disord. 1992;2(3):217-24.

43. Stockler S, Schutz PW, Salomons GS. Cerebral creatine deficiency syndromes: clinical aspects, treatment and pathophysiology. Subcell Biochem. 2007;46:149-66.

44. Rubio-Gozalbo ME, Heerschap A, Trijbels JM, De Meirleir L, Thijssen HO, Smeitink JA. Proton MR spectroscopy in a child with pyruvate dehydrogenase complex deficiency. Magn Reson Imaging. $1999 \mathrm{Jul} ; 17(6): 939-44$.

45. Barkovich AJ, Good WV, Koch TK, Berg BO. Mitochondrial disorders: analysis of their clinical and imaging characteristics. Am J Neuroradiol. 1993 Sep-Oct;14(5):1119-37.

46. Huisman TA, Thiel T, Steinmann B, Zeilinger G, Martin E. Proton magnetic resonance spectroscopy of the brain of a neonate with nonketotic hyperglycinemia: in vivo-in vitro (ex vivo) correlation. Eur Radiol. 2002 Apr; 12(4):858-61.
47. Gabis L, Parton P, Roche P, Lenn N, Tudorica A, Huang W. In vivo $1 \mathrm{H}$ magnetic resonance spectroscopic measurement of brain glycine levels in nonketotic hyperglycinemia. J Neuroimaging. 2001 Apr;11(2):209-11.

48. de Koning TJ, Jaeken J, Pineda M, Van Maldergem L, Poll-The BT, van der Knaap MS. Hypomyelination and reversible white matter attenuation in 3-phosphoglycerate dehydrogenase deficiency. Neuropediatrics. 2000 Dec;31(6):287-92.

49. Bachmann C. Long-term outcome of urea cycle disorders. Acta Gastroenterol Belg. 2005 Oct-Dec;68(4):466-8.

50. Bachmann C. Outcome and survival of 88 patients with urea cycle disorders: a retrospective evaluation. Eur J Pediatr. 2003 Jun;162 (6):410-6. 